\title{
Assessment of Bullying and Its Effect on Mental Health among Secondary School Students
}

\author{
Gehad Ahmed Abd Elhamid ${ }^{1}$, Ghada Mohamed Mourad ${ }^{2}$ and Faten Mohamed Ahmed ${ }^{3}$ \\ (1) Bachelor in Nursing Science 2014, (2) Professor of Psychiatric and Mental Health Nursing, \\ Faculty of Nursing, Ain Shams University and (3) Assistant professor of psychiatric and Mental \\ Health Nursing, Faculty of Nursing, Benha University
}

\begin{abstract}
Background: Bullying is a major problem in every aspect of life span is one of the biggest challenging areas within the field of education. Bullying perpetration and bullying victimization have been observed worldwide among adolescents and being victimized is associated with poor mental health. Aim: The current study aimed to assess bullying and its effect on mental health among secondary school students. Research design: This study used descriptive correlational design. Setting: This study was conducted at the secondary schools selected in Benha City. Sample: Multi stage random sample of 300 students. Tools of data collection: Data were collected using Socio-demographic Questionnaire, Olweus Bully and victim Questionnaire, Mental Health Inventory. Results: The common factors influenced bullying and were significantly associated with the occurrence of bullying in Benha secondary school such as: age $15<17$ years, female gender and residence in urban area. Physical and psychosocial victimization were the most prevalent type of victimization among students. There was significant positive correlation between total victim and total mental health. Conclusion: Almost of the studied subjects were victims. There was significance positive correlation between victim and mental health. Recommendations: The current study recommended that psychiatric mental health nurse, school health nurse and social workers provide psycho-educational program in schools to equip students social and interpersonal skills and know them the negative effect of bullying on colleagues.
\end{abstract}

Key words: Adolescence, Bullying, Mental health.

\section{Introduction}

Bullying exists in all communities, either in developed or developing societies from long years, it is considered the most common form of aggression and violence in schools. Multiple studies indicated that bullying makes schools to be unsafe places for students (Elsayed et al., 2019). Bullying is defined as repetitive violent behavior that occurs over time in relationships characterized by an imbalance in power and that can be manifested in many different ways. It is the systematic abuse among peers or a process of intentional and repetitive aggression, characterized by aggressive behavior that involves direct or indirect intimidation, insults, harassment, exclusion and/or discrimination (Oliveira et al., 2017).

Bullying can take different forms, it can be physical which may involve kicking, hitting, taking personal belonging, pushing, e. t. c., it can also be verbal which involve teasing maliciously, calling the victim names, being shouted at, being humiliated, threat, isolation e. t. c., it can also be social, for example social exclusion, spreading of rumors, extortion, false gossip, mocking e. t. c., and it can also be cyber for example bringing 
discomfort to others through the use of cell phones and the internet, humiliation (Lee et al., 2017).

Adolescence is arguably one of the most significant yet challenging developmental stages characterized by achieving numerous milestones, while dealing with rapidly unfolding emotional and social-relational incidents. At this stage of development, it is essential to have a healthy and successful completion of developmentally required tasks, as healthy adolescent progression impacts future biopsychosocial wellbeing (Zhang et al., 2019).

Mental health includes psychological and social wellbeing. It has a hug influence on how we think, feel and behave. A good state of mental health and wellbeing is required for an individual to carry out day to day functions. Mental health is important at every stage of an individual' s life. Mental health defined by (WHO, 2018), as being physically, mentally and socially wellbeing, and the absence of disease. It is interconnected to the promotion of wellbeing, prevention, treatment and rehabilitation of people affected by mental disorders.

Adolescence who are exposed to bullying report problems such as emotional trauma, a negative impact on school life, syndromes such as depression and anxiety, anxiety spectrum disorders such as social phobia and post-traumatic stress disorder, behaviors such as psychotic symptoms and somatic symptoms (e.g., stomach ache, headaches, dizziness, and back pain), sleep disorders, and physical damage in the short term (Çalışkan, et al., 2019).

Psychiatric Mental Health Nurses (PMHN) have the ability to assist in bullying prevention in schools by early detection by obtained information in active listening that becomes the basis for assessment and intervention activities. PMHN they are able to assist in implementing anti-bullying programs, assist victims, bullying and individuals who are present in a bullying incident, by providing counseling services, and they can also be utilized to teach students skills relating to their social contexts (Staples, 2016).

\section{Significance of the study}

Bullying has risen to become one of the most important forms of interpersonal violence among adolescents worldwide. However, concerns about school-based violence in Egypt have been raised by Egypt's National Center for Social and Criminal Research, which in a recent study of students in primary and secondary school found that $69 \%$ of students reported being bullied or experiencing aggression from other students (Elsayed et al., 2019).

Bullying among students not only decreases their academic performance but also causes mental health problems and physical injury. The bullying may refer to the situation of "getting picked on" by others. It happens to different types of repeatedly occurring threats, harassments, abuse, ill treatments and victimization. So, the present study conducted to assess bullying and its effect on mental health among secondary school students.

\section{Aim of this study}

The aim of this study was to assess bullying and its effect on mental health among secondary school students.

\section{Research questions:}

1. Is there bullying among secondary school students?

2. What is the effect of bullying on mental health among secondary school students? 


\section{Subject and methods}

\section{Research Design:}

Descriptive correlational design was utilized to achieve the aims of the study.

\section{Research setting:}

The study was conducted at the secondary schools selected in Benha City. A multistage random sample was used to select Benha City from Qaliubiya Government. Then, 3 secondary schools selected from Benha City (Umm Almuminin secondary school for girls is near from the educational administration, Qalubia national bank secondary school for boys is near from faculty of commerce, Joint technical advanced business school behind the train station) each school was selected 100 students by convenient sample. All grades (first, second and third grade) were included.

\section{Subject:}

\section{Sample size:-}

The target of this study will consist of 300 students from secondary schools in Benha city.

\section{Sample technique:-}

Multi stage random sample of 300 students from above mentioned setting who fulfilled the following inclusion criteria.

\section{Inclusion criteria:-}

- Both gender

- Willing to participate in the study

- Free from disabilities and psychiatric problem

\section{Tools of data collection:}

Two tools were used for data collection of the study:

Tool I: A structured interviewing questionnaire sheet
It was developed by the researcher it was concerned with the following

Socio-demographic data: It contained 7 items (age, sex, family size, living with, place of residence, number of siblings do you have, number of siblings go to school, violence in family).

\section{Tool II: Olweus Bullying Questionnaire (OBQ)}

It is adopted from Olweus, (1996). The OBQ is a self-report instrument composed of two subscale 23 items about victimization and 23 items about bullying. The OBQ assess frequency of various forms of practice bullying behavior that include (physical bullying behavior, verbal bullying behavior, psychosocial bullying behavior and cyber bullying behavior) and various forms from exposed to bullying behavior "victimization" this include (physical victim, verbal victim, psychosocial victim and cyber victim). Each item describes a different behavior occurred over the past month. This instrument respondent uses a 4 category likert scale. Give the following values to each response: Never $=1$; Once or twice a month $=2$; Around once a week $=3$, and; Several times a week $=4$.

\section{Scoring System}

Total scores of Olweus Bullying Questionnaire Scale were categorized as the following:

\begin{tabular}{|l|c|c|c|c|c|c|}
\hline \multirow{2}{*}{ Bullying } & \multirow{2}{*}{ Items } & \multirow{2}{*}{$\begin{array}{c}\text { Max } \\
\text { score }\end{array}$} & $\begin{array}{c}\text { non-bully } \\
<\mathbf{6 0 \%}\end{array}$ & \multicolumn{2}{|c|}{$\begin{array}{c}\text { Bully } \\
\mathbf{6 0 0 \%}\end{array}$} \\
\cline { 4 - 8 } & & & From & To & From & To \\
\hline Physical & 7 & 28 & 7 & 19 & 20 & 28 \\
\hline Verbal & 7 & 28 & 7 & 19 & 20 & 28 \\
\hline Psychosocial & 8 & 32 & 8 & 22 & 23 & 32 \\
\hline Cyber & 1 & 4 & 1 & 2 & 3 & 4 \\
\hline \multicolumn{1}{c|}{ Total } & $\mathbf{2 3}$ & $\mathbf{9 2}$ & $\mathbf{2 3}$ & $\mathbf{6 4}$ & $\mathbf{6 5}$ & $\mathbf{9 2}$ \\
\hline
\end{tabular}




\begin{tabular}{|l|c|c|c|c|c|c|}
\hline \multirow{2}{*}{ Victim } & \multirow{2}{*}{ Items } & \multirow{2}{*}{$\begin{array}{c}\text { Max } \\
\text { score }\end{array}$} & $\begin{array}{c}\text { Non- } \\
\text { victim } \\
<\mathbf{6 0 \%}\end{array}$ & \multicolumn{2}{|c|}{$\begin{array}{l}\text { Victim } \\
\mathbf{6 6 0 \%}\end{array}$} \\
\cline { 4 - 7 } & & & From & To & From & To \\
\hline Physical & 7 & 28 & 7 & 19 & 20 & 28 \\
\hline Verbal & 7 & 28 & 7 & 19 & 20 & 28 \\
\hline Psychosocial & 8 & 32 & 8 & 22 & 23 & 32 \\
\hline Cyber & 1 & 4 & 1 & 2 & 3 & 4 \\
\hline Total & 23 & 92 & 23 & 64 & 65 & 92 \\
\hline
\end{tabular}

Scores of each participant were categorized based on total scores of bulling and victim scores according to the following table:

\begin{tabular}{|l|c|c|}
\hline Items & Bully Score & Victim Score \\
\hline Pure Bully & $\geq 60 \%(65-92)$ & $<60 \%(23-64)$ \\
\hline Pure Victim & $<60 \%(23-64)$ & $\geq 60 \%(65-92)$ \\
\hline Bully/Victim & $\geq 60 \%(65-92)$ & $\geq 60 \%(65-92)$ \\
\hline Not Involved & $<60 \%(23-64)$ & $<60 \%(23-64)$ \\
\hline
\end{tabular}

Tool III. Mental Health Inventory (MHI)

It was developed by Lani, (2003). (MHI) include 38 items helps in the measure of overall emotional functioning for evaluating mental health issues such as anxiety, depression, behavioral control, positive effect, and general stress. This instrument respondent uses a 3 points likert-style response and it can generally be done without help. The test take approximately 5-10 minutes to administer. Give the following values to each response: All of the time =1; Some of the time $=2$, and; Non of the time $=3$.

\section{Scoring system}

Total scores of Mental Health Inventory Scale were categorized as the following:

\begin{tabular}{|c|c|c|c|c|c|c|c|c|c|}
\hline \multirow{2}{*}{ MHI } & \multirow{2}{*}{ Items } & \multirow{2}{*}{$\begin{array}{l}\text { Max } \\
\text { score }\end{array}$} & \multicolumn{2}{|c|}{ Poor } & \multicolumn{4}{|c|}{ Average Good } & \multirow{2}{*}{$\begin{array}{l}\text { the internal consistency of the tool by } \\
\text { ddministration of the same tools to the same }\end{array}$} \\
\hline & & & Fron & n to & from & to & From & to 2 & \\
\hline Anxiety & 7 & 21 & 7 & 11 & 12 & 16 & 17 & 21 & Condition it was \\
\hline Depression & 9 & 27 & 9 & 14 & 15 & 20 & 21 & 27 & punc \\
\hline Stress & 4 & 12 & 4 & 6 & 7 & 9 & 10 & $12^{b}$ & full \\
\hline Behavioral Control & 3 & 9 & 3 & 4 & 5 & 6 & 7 & 94 & \\
\hline Positive Effect & 15 & 45 & 15 & 24 & 25 & 34 & 35 & 45 & \\
\hline Total & 38 & 114 & 38 & 63 & 64 & 89 & 90 & 114 & \\
\hline
\end{tabular}

\section{Ethical consideration:}

All subjects were informed that participation in the study is voluntary; no name was included in the questionnaire sheet. Anonymity and confidentiality of each participant were respected and protected. Confidentiality were assured and subject were informed that the content of the tool were used for research purpose only and they have the right to refuse to participate in the study or withdrawal at any time.

\section{Pilot study:}

Before actual study apilot study was conducted on $10 \%$ of the students to test the reliability and validity of the tool, clarity of items and estimate the time needed for data collection. A sample of 30 students was recruited for the pilot study met the criteria for inclusion. The pilot study revealed no modifications in the tools. Subjects included in the pilot study were excluded from the main study sample.

\section{Content Validity of the tools:}

Tools were provided to a jury of 5 experts in the psychiatric nursing (1 professor, 1 assistant professor and 3 lecturer). Tools were checked for the relevancy, clarity, comprehensiveness and applicability of the questions. The tool proved to be valid. According to their opinions, modifications were done.

\section{Reliability of the tool:}

It was applied by the researcher for testing 


\section{Field work:}

The interviewed questionnaire was conducted by the researcher for the students in selected secondary schools, after getting of:

1- An official permission from faculty of nursing/Benha university to the administrators of the secondary schools setting to conduct the study.

2- Oral informed consent was obtained from students.

3- Brief description of the purpose of the study was given to the students.

4- The data collected were done through visiting the selected schools from 9 am to 1 $\mathrm{pm}$, three days per week by rotation. The fieldwork was performed in the following sequence: In each school, study aim and importance was clarified to the head master and class teachers to gain their support and cooperation. In each class, the researcher explained the study purpose to the students. Questionnaire sheets were distributed between students in the class and they were asked to fill them individually. Each interview lasted for 30 to 40 minutes. Data were collected throughout the period from beginning of October, 2019 till December, 2019.

\section{Statistical Analysis:}

The collected data were organized, analyzed using appropriate statistical significance tests. The data were collected and coded using the Computer Statistical Package for Social Science (SPSS), version 21, and was also used to do the statistical analysis of data. Data were presented using descriptive statistics in the form of frequencies and percentages. A Person Correlation test was used to compare study variables.

\section{Degrees of the significance of results were considered as follow:}

p-value $>0.05$ Not significant (NS)

$\mathrm{p}$-value $\leq 0.05$ Significant $(\mathrm{S})$

p-value $\leq 0.01$ Highly Significant (HS) informed that the content of the tool were used for research purpose only and they have the right to refuse to participate in the study or withdrawal at any time. 


\section{Results}

Table 1 illustrated the Sociodemographic characteristics of the studied subjects. It is found that the mean age of the studied subjects was $16.38 \pm 1.02$ years. It is found also that females constituted slightly less than sixty $(58.3 \%)$ of the studied subjects, Regarding to the family size, half $(50 \%)$ of the studied subjects have from 3-5 individual in his family. The table presented that the studied children almost (96.7\%) are living with their parents. The same table reveals that slightly less than sixty $(60 \%)$ of the studied children are living in urban areas. Around three quadraunt $(69.9 \%)$ of the studied children have from 1 to 3 child in their family. This table also shows that about two fifth $(41.7 \%)$ of the studied children have not siblings go to school. Regarding to violence in family, the table reveals that the majority $(81.7 \%)$ of the studied children are not exposed to violence in their family.

Table 2 shows that the majority $(90.7 \%, 90 \%)$ of the studied subject have physical and psychosocial victimization, almost $(85.3 \%)$ of the studied subject have verbal victimization and about two thirds $(65.3 \%)$ of the studied subject have cyber victimization.

Table 3 shows that slightly more than the third $(32 \%)$ of the studied subject have psychosocial bullying, near the third (28.7\%) of the studied subject have verbal bullying, about the quadrant $(23.3 \%)$ of the studied subject have cyber bullying and $(12.3 \%)$ of the studied subject have physical bullying.

Table 4 shows that almost $(67.3 \%)$ of the studied subject are pure victims, near the quadrant $(20.7 \%)$ of the studied subject are bully/victims, (9.3\%) of the studied subject are not involved and $(2.7 \%)$ of the studied subject are pure bully.

Table 5 shows that almost $(67 \%, 62 \%, 61,4 \%)$ of the studied subject have average positive effect, stress and anxiety and more than half $(56.3 \%, 52.0 \%)$ of the studied subject have average behavioral control and depression.

Figure 1 Shows that almost (77\%) of the studied subjects have average mental health.

Table 6 shows that there is significant positive correlation between total mental health and age (P 0.01).

Table 7 shows that there is significant positive correlation between total victim and total mental health (P 0.01).

Table 8 shows that there is significant positive correlation between verbal victim and physical bullying (P 0.05). 
Gehad Ahmed Abd Elhamid, Ghada Mohamed Mourad and Faten Mohamed Ahmed

Table (1): Socio-demographic Characteristics among Studied Subjects $(n=300)$.

\begin{tabular}{|c|c|c|}
\hline Socio-demographic Characteristics & $\mathbf{N}$ & Percentage \\
\hline \multicolumn{3}{|l|}{ Age } \\
\hline $15>17$ & 195 & 65.0 \\
\hline $17-18$ & 105 & 35.0 \\
\hline Mean \pm SD & $16.38 \pm 1.02$ & \\
\hline \multicolumn{3}{|l|}{ Sex } \\
\hline Male & 125 & 41.7 \\
\hline Female & 175 & 58.3 \\
\hline \multicolumn{3}{|l|}{ Family Size } \\
\hline $3-5$ & 150 & 50.0 \\
\hline $6-8$ & 130 & 43.3 \\
\hline $9-10$ & 20 & 6.7 \\
\hline \multicolumn{3}{|l|}{ Living with } \\
\hline Parents & 290 & 96.7 \\
\hline Relative & 10 & 3.3 \\
\hline \multicolumn{3}{|l|}{ Residence } \\
\hline Rural & 120 & 40.0 \\
\hline Urban & 180 & 60.0 \\
\hline \multicolumn{3}{|l|}{ How many sibling do you have? } \\
\hline 0 & 5 & 1.7 \\
\hline $1-3$ & 210 & 69.9 \\
\hline $4-7$ & 85 & 28.4 \\
\hline \multicolumn{3}{|l|}{ How many of siblings go to school } \\
\hline 0 & 125 & 41.7 \\
\hline 1 & 75 & 25.0 \\
\hline 2 & 55 & 18.3 \\
\hline 3 & 20 & 6.7 \\
\hline 4 & 15 & 5.0 \\
\hline 5 & 10 & 3.3 \\
\hline \multicolumn{3}{|l|}{ Violence in family } \\
\hline No & 245 & 81.7 \\
\hline Yes & 55 & 18.3 \\
\hline
\end{tabular}

Table (2): Subscales Score of Olweus Victim Questionnaire ( $=300)$.

\begin{tabular}{|l|c|c|}
\hline \multicolumn{1}{|c|}{ Items } & N & Percentage \\
\hline Physical & 272 & 90.7 \\
\hline Verbal & 256 & 85.3 \\
\hline Psychosocial & 270 & 90.0 \\
\hline Cyber & 196 & 65.3 \\
\hline Total & 264 & 88.0 \\
\hline
\end{tabular}

Table (3): Subscales Score of Olweus Bully Questionnaire $(\mathbf{n = 3 0 0 )}$.

\begin{tabular}{|l|c|c|}
\hline & N & Percentage \\
\hline Physical & 37 & 12.3 \\
\hline Verbal & 86 & 28.7 \\
\hline Psychosocial & 96 & 32.0 \\
\hline Cyber & 70 & 23.3 \\
\hline Total & 70 & 23.3 \\
\hline
\end{tabular}


Table (4): Prevalence of bullying among studied subjects $(n=300)$.

\begin{tabular}{|c|c|c|}
\hline Items & N & Percentage \\
\hline Pure victims & 202 & 67.3 \\
\hline Pure bully & 8 & 2.7 \\
\hline Bully/victims & 62 & 20.7 \\
\hline Not involved & 28 & 9.3 \\
\hline Total & 300 & 100.0 \\
\hline
\end{tabular}

Table (5): Mental Health Inventory (MHI) Subscales among Studied Subjects $(\mathrm{n}=300)$.

\begin{tabular}{|l|c|c|c|c|c|c|}
\hline \multirow{2}{*}{ Items } & \multicolumn{2}{c}{ Poor } & \multicolumn{2}{c|}{ Average } & \multicolumn{2}{c|}{ Good } \\
\cline { 2 - 7 } & $\mathbf{N}$ & $\mathbf{\%}$ & $\mathbf{N}$ & $\mathbf{\%}$ & $\mathbf{N}$ & \% \\
\hline Anxiety & 15 & 5.3 & 185 & 61.4 & 100 & 33.3 \\
\hline Depression & 45 & 16.0 & 160 & 52.0 & 95 & 32.0 \\
\hline Stress & 25 & 7.3 & 185 & 62.0 & 90 & 30.7 \\
\hline Behavioral control & 75 & 25.0 & 170 & 56.3 & 55 & 18.7 \\
\hline Positive effect & 60 & 20.0 & 200 & 67.0 & 40 & 13.0 \\
\hline Total & 20 & 6.7 & 230 & 77.0 & 50 & 16.3 \\
\hline
\end{tabular}

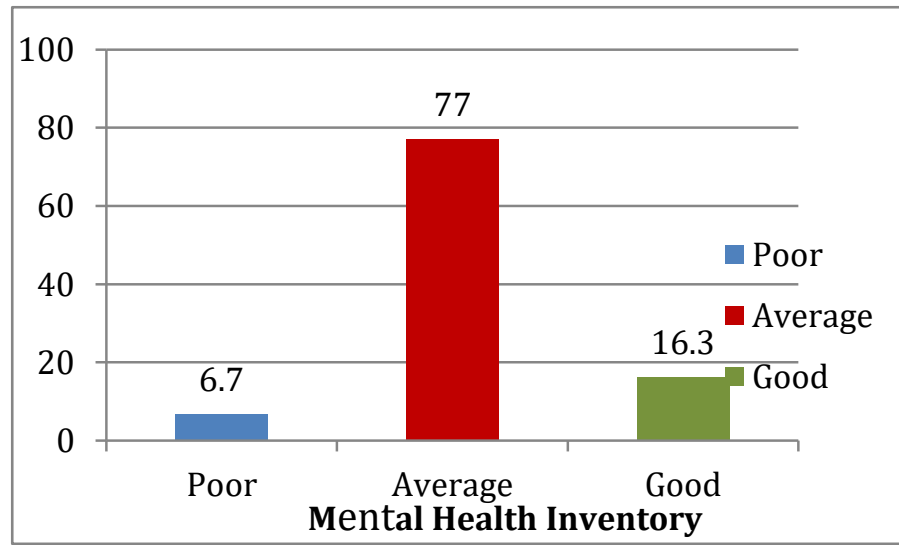

Figure (1): Total Mental Health Inventory (MHI) among Studied Subjects.

Table (6): Correlation between Age, Gender, Total Subscales Score of Olweus Bully and Victim Questionnaire and Total Mental Health Inventory (MHI) Subscales among Studied Subjects $(\mathbf{n}=\mathbf{3 0 0})$.

\begin{tabular}{|l|c|c|c|c|}
\hline \multirow{2}{*}{ Items } & \multicolumn{2}{c|}{ Age } & \multicolumn{2}{c|}{ Gender } \\
\cline { 2 - 5 } & $\mathbf{R}$ & $\mathbf{P}$ & $\mathbf{R}$ & $\mathbf{P}$ \\
\hline Total Bullying & 0.016 & 0.789 & 0.044 & 0.452 \\
\hline Total Victim & -0.053 & 0.362 & -0.079 & 0.170 \\
\hline Total mental health & -0.170 & $0.003 * *$ & 0.004 & 0.939 \\
\hline
\end{tabular}

r Pearson Correlation.

* Correlation is significant at the 0.05 level.

** Correlation is significant at the 0.01 level. 
Table (7): Correlation between Total Subscales Score of Olweus Bully and Victim Questionnaire and Total Mental Health Inventory (MHI) Subscales among Studied Subjects ( $n=300)$.

\begin{tabular}{|l|c|c|}
\hline \multirow{2}{*}{} & \multicolumn{2}{|c|}{$\begin{array}{c}\text { Total Mental Health Inventory } \\
\text { (MHI) }\end{array}$} \\
\cline { 2 - 3 } & R & P \\
\hline $\begin{array}{l}\text { Total } \\
\text { Bullying }\end{array}$ & 0.028 & 0.633 \\
\hline $\begin{array}{l}\text { Total } \\
\text { Victim }\end{array}$ & 0.011 & $0.006^{* *}$ \\
\hline
\end{tabular}

r Pearson Correlation.

* Correlation is significant at the 0.05 level.

** Correlation is significant at the 0.01 level.

Table (8): Correlation between Olweus Bully and Victim Questionnaire Subscales among Studied Subjects $(\mathrm{n}=300)$.

\begin{tabular}{|l|c|c|c|c|c|c|c|c|c|c|}
\hline & \multicolumn{9}{|c|}{ Olweus Bully Questionnaire } \\
\cline { 2 - 11 } & \multicolumn{2}{|c|}{$\begin{array}{c}\text { Physical } \\
\text { Bullying }\end{array}$} & \multicolumn{2}{c|}{$\begin{array}{c}\text { Verbal } \\
\text { Bullying }\end{array}$} & \multicolumn{2}{c|}{$\begin{array}{c}\text { Psychosocial } \\
\text { Bullying }\end{array}$} & \multicolumn{2}{c|}{$\begin{array}{c}\text { Cyber } \\
\text { Bullying }\end{array}$} & \multicolumn{2}{|c|}{ Total Bullying } \\
\cline { 2 - 11 } & $\mathbf{r}$ & $\mathbf{P}$ & $\mathbf{r}$ & $\mathbf{P}$ & $\mathbf{R}$ & $\mathbf{P}$ & $\mathbf{r}$ & $\mathbf{p}$ & $\mathbf{R}$ & $\mathbf{P}$ \\
\hline $\begin{array}{l}\text { Olweus Victim } \\
\text { Questionnaire }\end{array}$ & & & & & & & & & & \\
\hline $\begin{array}{l}\text { Physical Victim } \\
\text { Verbal Victim }\end{array}$ & -0.059 & 0.307 & 0.036 & 0.529 & 0.079 & 0.174 & 0.099 & 0.087 & 0.041 & 0.474 \\
\hline $\begin{array}{l}\text { Psychosocial } \\
\text { Victim }\end{array}$ & -0.032 & 0.581 & 0.032 & 0.585 & 0.045 & 0.437 & 0.071 & 0.218 & 0.029 & 0.616 \\
\hline Cyber Victim & 0.004 & 0.939 & 0.043 & 0.463 & 0.058 & 0.317 & 0.033 & 0.566 & 0.046 & 0.432 \\
\hline Total Victim & -0.073 & 0.205 & 0.001 & 0.989 & 0.033 & 0.568 & 0.088 & 0.127 & 0.003 & 0.955 \\
\hline
\end{tabular}

r Pearson Correlation.

* Correlation is significant at the 0.05 level.

** Correlation is significant at the 0.01 level.

\section{Discussion}

Bullying has become one of the hot topics in schools across the world. Bullying is a subset of aggressive behavior, which occurs mainly between children and adolescents in schools. It involves repetitive and intentional use of power by one individual or group against another, causing physical or psychological damage (Galal et al., 2019). Children can be directly involved in bullying either as bullies (i.e., perpetrators) or victims (i.e., targets) or bully/victims who are involved in bullying both as bullies and as victims (Galal et al., 2019). Bullying and mental health problems are important phenomena that can have a negative impact on mental well-being among adolescents (Nguyen et al., 2019).

Regarding the demographic characteristics of the studied subjects, the present study was carried out on 300 student that revealed; the mean age of them was (16.38 $\pm \mathbf{1 . 0 2})$ This showed that all the students were adolescents and therefore are prone to 
peer pressure, drug abuse, and other indiscipline behaviors which lead to bullying, in addition to bullying may complicated by normal physiological and psychological changes that occur in puberty. This is similar to findings of the study about factors contributing to bullying among students in public secondary schools in kiambu district in kinya done by Kahunga (2014), reported that majority $(87.5 \%)$ of involved students in his study had age below18 years while $12.5 \%$ had age above 18 years.

Regarding the sex, the present study showed that slightly less than sixty of the studied subjects are females, this may be attributed to The findings of the present study agreed with Kijakovic \& Hunt, (2015) conducted study about Incidence of bullying and victimization among adolescents in New Zealand, reported that female students were $52 \%$ and $48 \%$ were males in their study sample. In addition to Eskisu, (2014) conducted study on "The relationship between bullying, family function and perceived social support among high school students, involved 683 participants from secondary schools in Ankara, Turkey, stated that female were more than half $(52 \%)$ of sample while males were $48 \%$, also found that the middle grade was the largest in size and this finding is agree with the present study. This findings are disagreed by Elmasry et al. (2016) study was conducted in Zagazig Center, Sharkia Governorate, Egypt, "with 574 participants of adolescent students" who found that more than half $(54.4 \%)$ of his sample were males and more than two-thirds (45.6\%) were females, nearly similar to the result of Seo et al. (2017) in korea the sample included" 2936 adolescents participants", reported $57.5 \%$ were males and $42.5 \%$ were females of their studied sample. In addition to the results of study on "The experience of bullying among secondary school students in Greek schools" done by Athanasiades \& Kouimtzis, (2016) showed that more than half of the sample were boys.

Regarding to the family size, half of the studied subjects had 3-5 person in his family.

Regarding to living with the present study revealed that almost of the studied subjects living with their parents, this may be attributed to our cultures, norms and customs of eastern community. This results are nearly similar to Han et al. (2017) done a study on School bullying in urban china: Prevalence and correlation with school climate included 3777 students in China, found that most of the students lived with their parents $(73.28 \%)$ while more than quarter $(26.78 \%)$ of them lived with one parent or others.

Regarding the place of residence the present study showed that slightly less than sixty $(60 \%)$ of the studied children are living in urban areas. This may be related to the study was conducted in Benha city schools and not included rural schools. This finding is nearly similar to the result of O'Donnells, (2015) conducted a study on The impact of bullying and act variables on meaning in life for adolescents in Colorado, the sample included" 186 participants, reported that twofifth $(40.0 \%)$ of his studied sample lived in rural area while three-fifth $(60.0 \%)$ of them lived in urban area. The findings of the present study disagreed with Saini \& Balada, (2019) who assessed Bullying, victimization and fighting in secondary schools conducted in Hisar district of Haryana state, India included 1070 students in sample, reported that more than half of their study's participants were from rural area.

Regarding number of sibling do you have, around three quadrant $\mathbf{( 6 9 . 9 \% )}$ of the studied children had from 1 to 3 child in their family. 
Regarding number of sibling go to school, about two fifth of the studied children had not siblings go to school.

Regarding to violence in family, the majority of the studied children were not exposed to violence in their family.

The present study indicated that, almost of the studied children had physical and psychosocial victimization. This may be attributed to the most direct and obvious physical symptoms of victimization are injuries as a result of an aggressive physical action such as assault or sexual victimization. Other physical symptoms that are not a result of injury may be indirectly caused by victimization through psychological or emotional responses. the experience of being victimized may cause an individual to feel vulnerable or helpless, being bullied is associated with poor psychological wellbeing of an individual and it creates insecurity and insecure environment with negative selfworth and respect and individual who have being bullied undergo emotional stress including feeling of powerless, being angry and frightened. This result was consistent with the results of Owuamanam, (2015) conducted a study on Prevalence of Bullying among Secondary School Students in Ondo State, Nigeria "with sample of 600 students", indicated that the psychological type of victimization was the most common type $(58.3 \%)$ among secondary school students in Ondo state, Nigeria. This result was inconsistent with Garmaroudi et al. (2014) found that verbal victimization was the most common type reported by more than threefifth $(61.3 \%)$ of students and physical victimization was( $47.6 \%)$. Also, the results of current study are disagree with Turkmen et al. (2013) conducted a study on Bullying among high school students in Turkey "sample 6127 participants" reported that verbal victimization was occurred more than physical victimization in schools $(47.3 \%$ and $41.2 \%$ respectively). Also, this result was inconsistent with Elsayed et al. (2019) who conducted a study about Factors Influence Bullying Among Secondary School Students in Sohag City and found that verbal victimization was the most widely performed type of victimization reported by about threefifth (59.2\%) of students and physical victimization was the least common type of victimization $(32.8 \%)$.

Regarding bullying behavior, The present study showed that slightly more than the third $\mathbf{3 2 \%})$ of the studied subject had psychosocial bullying. This can be attributed to having low self-esteem, others may like conflict and aggression, feeling angry or frustrated and some may be emotionally neglected, bullied, abused or be experiencing violence themselves and lack understanding of others mental state, poor self-control and judgment which facilitate in impulsive aggressive behavior. This result was inconsistent with Nasheeda et al. (2017) who conducted a study about Relationships between bullies, victims and mental health issues among Adolescents and found that verbal bullying is the most common type of bullying among males and females in Maldives.

Regarding prevalence of bullying among studied subjects, the present study revealed that almost of the studied subject are pure victims. This finding may be attributed to according to bio psychosocial diathesis-stress model, when the biological and cognitive vulnerabilities interact with environmental stressors, such as being unpopular among friends, poor and unstable relationships with parents places individuals at risk of being bullied. This finding supported by Saini \& Balada, (2019) reported that majority $(81.31 \%)$ of students participated in their 
study were victims of bullying. Also this result was in the same line with Elsayed et al. (2019) who conducted a study about Factors Influence Bullying among Secondary School Students in Sohag City and found that majority $(78.7 \%)$ of the sample were victims of bullying. Moreover the findings of the present study disagreed with the results of Alavi et al. (2015) found that bullying victimization was $48.53 \%$ among students. This result was inconsistent with Galal et al. (2019) who conducted a study about Prevalence and correlates of bullying and victimization among school students in rural Egypt and found that the highest prevalence was for bully-victims (57.8\%), 9.5\% were unique bullies and $10.5 \%$ were unique victims.

Also, regarding mental health inventory, the present study found that the majority of the Studied Subjects had average positive effect, stress and anxiety. This finding may be attributed to These findings do raise some serious concerns as literature suggest that social factors such as being unpopular among friends, having fewer friends, unstable relationships places stress on the individuals. Stress is considered as a contributing element to poor functioning of immune system and causes mental problems, such as anxiety, depression and other psychological illnesses. This result was inconsistent with Nasheeda et al. (2017) who conducted a study about Relationships between bullies, victims and mental health issues among Adolescents and found that findings on the types of mental health issues among adolescents in Maldives revealed that $23 \%$ reported being anxious frequently, where as $24 \%$ reported being depressed, $77.6 \%$ reported low behavior control, $37 \%$ were low on general positive affect, $55 \%$ had weaker emotional ties with significant others in their lives.
Regarding total mental health inventory (MHI) among studied subjects, the present study revealed that almost of the studied subjects had average mental health. This finding may be attributed to having few friends, having feeling of loneliness, social disadvantage as poverty or debt. This result was inconsistent with Musa, (2016) who conducted a study about Association between bullying, mental health and school performance in form one pupils in secondary schools in Kisumu and found that there was poor mental health.

The present study showed that there was significant positive correlation between age and mental health (P 0.01). This finding may be attributed to multiple factors determine mental health outcomes during adolescence include a desire for greater autonomy, pressure to conform with peers, exploration of sexual identity, and increase access to and use of technology. Media influence and gender norms can exacerbate the disparity between an adolescence lived reality and their perceptions or aspirations for the future. Other important determinants include the quality of their home life and relationships with peers. Violence (bullying) and socioeconomic problems are recognized risks to mental health. This result was inconsistent with the result of Nasheeda et al. (2017) who conducted a study about Relationships between bullies, victims and mental health issues among Adolescents and found that there is no relationship between age and mental health among adolescents in Maldives

The present study showed that there was significant positive correlation between total victimization and mental health inventory ( $P$ $0.01)$. This finding may be attributed to the notion supports biopsychosocial model of stress, as bullying is a stressful event which leaves the individual very vulnerable and 
helpless. Thus, these feeling will cause negative thoughts which will affect their mental state and when victims experience bullying their bodies respond with biochemical reactions by providing more glucose to compensate for the oxygen and energy to fight or flight the situation. This result was consistent with the result of Nasheeda et al. (2017) who conducted a study about Relationships between bullies, victims and mental health issues among Adolescents and found that the relationship between victimization and mental health revealed that being bullied has a significant positive relationship on mental health. Also this result was in the same line with Musa, (2016) who conducted a study about Association between bullying, mental health and school performance in form one pupils in secondary schools in Kisumu and found that there was strong association between being bullied and mental health.

The present study showed that there was significant positive correlation between verbal victim and physical bullying ( $\mathrm{P}$ 0.05). This can be attributed to the person who does physical bullying takes advantage of his strong body and the victim is often weakly built and cannot defend himself physically, so he uses words to breathe out of his anger and the harm he is inflicting on him. Verbal victim is considered easy and does not require physical strength as other type. This result was consistent with Johansoon \& Englund, (2020) who conducted a study on Cyberbullying and its relationship with physical, verbal, and relational bullying and found that relationship between verbal victim and physical bullying.

\section{Conclusion}

The common factors influenced bullying and were significantly associated with the occurrence of bullying in Benha secondary school such as: age 15>17 years, female gender and residence in urban area. Physical and psychosocial victimization were the most prevalent type of victimization among students. Psychosocial bullying was the most common prevalent type of bullying behavior among students. Almost of the studied subjects were pure victims. Almost of the studied subject had average positive effect, stress and anxiety. Almost of the studied subjects had average mental health. There was significance positive correlation between age and mental health. There was significance positive correlation between victim and mental health. There was significance positive correlation between verbal victim and physical bullying.

\section{Recommendations}

- Awareness program for family and community about signs and symptoms, factors influence bullying in schools and how to deal with it.

- Provide psycho-educational program by psychiatric mental health nurse, school health nurse and social workers in schools to equip students social and interpersonal skills and know them the negative effect of bullying on colleagues.

- PMHN should be encourage students themselves to actively participate in the supervision and prevention of bullying.

- Put enacted laws regarding bullying, should students and community know legal consequences for practice bullying behavior.

- Develop intervention program for students in schools to help in manage bullying.

- Develop a training program for staff in a school setting on how to handle a bullying episode, how to report it, and how to access resources. 
- Further follow-up of students by PMHN and school nurse for predicting those at higher risk of behavioral abnormalities.

\section{References}

Alavi, N., Roberts, N., Sutton, C., Axas, N. \& Repetti, C. (2015). Bullying victimization among adolescents referred for urgent psychiatric consultation: Prevalence and association with suicidality. Canadian journal of psychiatry, Vol.60, No.10, Pp; 427-431.

Athanasiades, C. \& Kouimtzis, D. (2016). The experience of bullying among secondary school students in Greek schools, Journal of psychology in schools.Vol.(47),No.(4),Pp.328-341.

Çalışkan, Z., Evgin, D., Bayat, M., Caner, N., Kaplan, B., Öztürk, A., \& Keklik, D. (2019). Peer bullying in the preadolescent stage: Frequency and types of bullying and the affecting factors. Journal of Pediatric Research, 6(3), 169-179.

El masry, N., Fouad, A., Khalil, D. \& Sherra, K. (2016). Physical and verbal aggression among adolescents school students in sharkia,Egypt prevalence and risk factors. Egypt journal psychiatry, Vol.37,No.(3): Pp.166-173.

El-sayed, R.N., Kotb, S.A. \& Ibrahim, E. (2019). Factors Influence Bullying Among Secondary School Students in Sohag City. Assiut Scientific Nursing Journal, 7(18), 122-133.

Eskisu, M. (2014). The relation ship between bullying, family function and perceived social support among high school students, journal of social and behavioral sciences, Vol.(159),Pp.492-496.

Galal, Y. S., Emadeldin, M. \& Mwafy, M.A.(2019). Prevalence and correlates of bullying and victimization among school students in rural Egypt. Journal of the
Egyptian Public Health Association, 94(1), 18.

Garmaroudi, G., Mohammad, K., Omidvari, S. \& Jafarpour, S. (2014).Prevalence of bullying among Iranian middle school students,journal of health education and health promotion (HEHP), Vol.2,No.3,Pp9-20.

Han, Z., Zhang, G. \& Zhang, H. (2017).School bullying in urban china: Prevalence and correlation with school climate, International Journal of Environmental Research and Public Health, vol.(14),No.(10),Pp.1-13. 1116; doi:10.3390/ijerph1 4101116

Johansson, S. \& Englund, G. (2020). Cyberbullying and its relationship with physical, verbal, and relational bullying: a structural equation modelling approach. Educational Psychology, 1-18.

Kahunga, J. (2014). Factors contributing to bullying among students in public secondary school in kiamu district,Kenya.Unpublished master thesis of education of Kenyatta university.

Kijakovic, M. \& Hunt, C. (2015). Incidence of bullying and victimization among adolescents in Newzealand,Journal of Psychology, Vol.(44),No.(2),Pp.57-67.

Lani, J. (2003). Mental Health Inventory (MHI). Statistics Solutions http://www.statisticssolutions.com

Lee, K., Guy, A., Dale, J., \& Wolke, D. (2017). Does psychological functioning mediate the relationship between bullying involvement and weight loss preoccupation in adolescents? A two-stage cross-sectional study. International journal of behavioral nutrition and physical activity, 14(1), 38.

Musa, R.I. (2016).Association between bullying, mental health and school performance in form one pupils in 
secondary schools in Kisumu (Doctoral dissertation, university of Nairobi).

Nasheeda, A., Hassan, N. C., \& Hassan, S. A. (2017). Relationships between bullies, victims and mental health issues among adolescents.

Nguyen, H. T. L., Nakamura, K., Seino, K., \& Al-Sobaihi, S. (2019). Impact of parent-adolescent bonding on school bullying and mental health in Vietnamese cultural setting: evidence from the global school-based health survey. BMC psychology, 7(1), 16.

O'Donnells, B. (2015). The impact of bullying and act variables on meaning in life for adolescents Unpublished Master thesis of science, Colorado state university.

Oliveira, F., Menezes, T., Traffi, G. \& Oliveira, G. (2017). Bullying effect on students performance,Journal of Economia,Vol(19),No(1),Pp57-73.

Olweus, D. (1996). The Revised Olweus Bully/Victim Questionaire. Bergen: Research Center for Health Promotiom.

Owuamanam, O. (2015). Prevalence of Bullying among Secondary School Students in Ondo State,Nigeria,2015 European Scientific Journal, vol.11, No.20 Pp: $1857-7881$.

Saini, V. \& Balada, S. (2019). Bullying, victimization and fighting :Extent in secondary children,International Journal of current microbiology and applied Sciences, Vol.8,No3, Pp74-81.

Seo, H., Jung, Y., Kim, M. \& Bahk, W. (2017). Factors associated with bullying victimization among Korean adolescents, journal of Neuropsychiatric disease and treatment,vol.(13),no.(4), Pp.2429-2435.

Staples, J. (2016). Understanding School Social Workers' Roles in Bullying
Prevention and Intervention. the Faculty of the School of Social Work, Catherine University. Master paper. Minnesota.

Turkmen, N., Dokgoz, H., Akgoz, S., Ern, B., Vural, P. \& Polat, O., (2013). Bullying among high school students,journal of clinical medicine, Vol.8,No(2),Pp:143-152.

World Health Organization (2018). Constitution of the World Health Organization. Geneva: Author. Retrieved July 28, 2018, from http://apps.who.int/gb/bd/PDF/bd47/EN/co nstitution-en.pdf?ua=1

Zhang, A., Liu, C., Bornheimer, L. A., Solomon, P. \& Wang, K. (2019). The indirect effect of bullying on adolescent self-rated health through mental health: A gender specific pattern. Children and Youth Services Review, 104, 104385. 


\section{تقييم التتمر وتأثيرة على الصحة العقلية بين طلاب المدارس الثانوية}

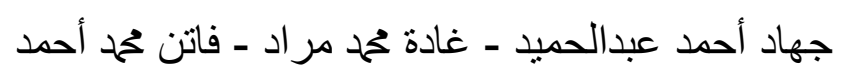

يمثل التنمر مشكلة رئيسية في كل جانب من جوانب الحياة وهي واحدة من أكبر المشكلات الصعبة في مجال

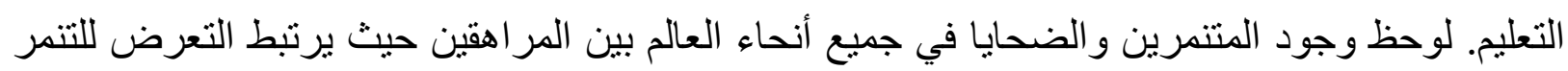
بضعف الصحة العقلية. لذلك هدفت هذه الدراسة إلى تقييم التتمر وتأثيره على الصحة العقلية بين طلاب

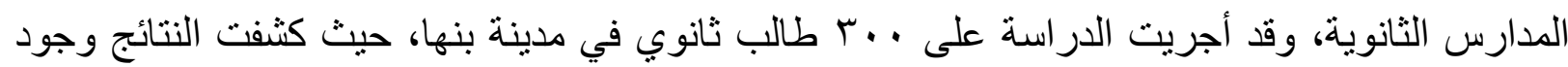

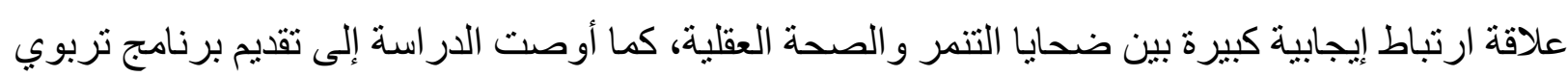

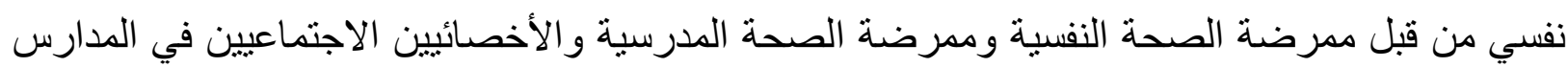

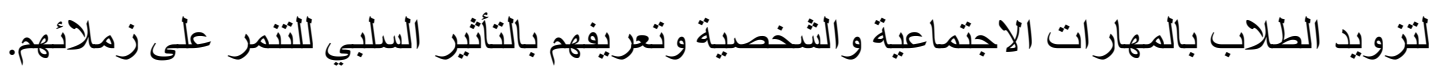

